\title{
ETNOMATEMATIKA: EKSPLORASI DALAM TARIAN TRADISIONAL PADA PEMBUKAAN ASIAN GAMES 2018
}

\author{
Maryati 1)* dan Wira Pratiwi ${ }^{2)}$ \\ 1) SMP Muhammadiyah 1 Tepus, Gunungkidul, Yogyakarta, 55881 \\ 2) Program Studi Pendidikan Matematika, Universitas Muhammadiyah Jakarta, 15419 \\ *maryati1708050021@webmail.uad.ac.id
}

\begin{abstract}
Abstrak
Tujuan dari penelitian ini adalah untuk mengeksplorasi hubungan antara matematika dengan budaya, khususnya dalam tarian tradisional pada pembukaan Asian Games 2018. Penelitian ini menggunakan pendekatan etnografi yang merupakan sebuah pendekatan empiris dan teoritis untuk mendapatkan gambaran dan analisis mendalam tentang sebuah budaya berdasarkan catatan lapangan yang telah diperoleh dari hasil pengumpulan data. Hasil penelitian ini menunjukkan bahwa dalam tarian tradisional pada pembukaan Asian Games 2018 yaitu tari Saman memiliki berbagai konsep matematika, seperti konsep bangun datar dan himpunan. Oleh karena itu, tarian tradisional ini dapat digunakan sebagai starting point atau konteks dalam pembuatan desain pembelajaran untuk anak sekolah dasar maupun sekolah menengah. Selain itu, dapat mengubah paradigma anak dan masyarakat bahwa matematika memiliki hubungan dengan aktivitas sehari-hari dan matematika memiliki hubungan dengan budaya serta dapat dipelajari dengan cara yang menyenangkan.
\end{abstract}

Kata Kunci: etnomatematika, tarian tradisional, etnografi.

\section{PENDAHULUAN}

Kurikulum 2013 menuntut agar dalam pelaksanaan pembelajaran siswa diberi kebebasan berpikir, memahami masalah, membangun strategi penyelesaian masalah, mengajukan ide-ide secara bebas dan terbuka (Sinambela, 2017). Lebih lanjut Sinambela (2017) menjelaskan bahwa kegiatan guru dalam pembelajaran adalah melatih dan membimbing siswa berpikir kritis dan kreatif dalam menyelesaikan masalah. Selain itu guru juga harus pandai memilih strategi pembelajaran yang tepat dan sesuai dengan keadaan kelas (Purnamasari, dkk, 2017). Salah satu strategi pembelajaran untuk meningkatkan berpikir kritis yaitu dengan memfasilitasi atau memberi kesempatan siswa untuk menyelesaikan suatu permasalahan dalam kehidupan. Hal ini sesuai dengan abad 21, yaitu menurut Sudirman, Rosyadi, dan Lestari (2017) menjelaskan bahwa konsep- 
konsep matematika dapat dikaitkan dengan situasi dunia nyata.

Era globalisasi yang sedang berkembang di abad 21 memungkinkan berbagai macam budaya dari negara lain dengan mudah masuk di Indonesia. Pegaruh budaya-budaya baru tersebut menyebabkan gaya hidup masyarakat ikut berubah dan mulai meninggalkan budaya asli Indonesia. Pembelajaran yang menanamkan nilai-nilai budaya Indonesia diperlukan dalam meningkatkan rasa cinta tanah air siswa (Kusuma, 2016).

Matematika adalah pengetahuan yang melekat dalam aktivitas kehidupan dan sangat dekat dengan budaya (Maryati dan Prahmana, 2018). Dalam pembelajarannya, matematika dapat diajarkan dengan menggunakan budaya sebagai sumber belajar (Putri, 2017). Hal ini menunjukkan bahwa konsep matematika dapat dikontekstualkan melalui aktivitas-aktivitas sehari-hari yang berhubungan dengan budaya.

Etnomatematika adalah praktik matematika dalam kelompok budaya (Haryanto, dkk. 2017). Lebih lanjut Vasquez (2017) menjelaskan bahwa etnomatematika tidak hanya membahas pengetahuan matematika tetapi juga bahasa, nilai, perilaku, pengetahuan, dan praktik kelompok budaya menyebar di lingkungan tertentu. Hal ini diperkuat dengan hasil penelitian Dahlan dan Permatasari (2018) menunjukkan bahwa bahan ajar berbasis etnomatematika mampu memfasilitasi siswa dalam mengkonstruksi pengetahuan matematika secara induktif.

Indonesia merupakan sebuah negara dengan keanekaragaman budaya yang berbeda-beda. Tarian tradisional juga merupakan salah satu aktivitas budaya yang ada dalam masyarakat. Tari adalah gerakangerakan dari seluruh bagian tubuh yang disusun selaras dengan irama musik serta mempunyai maksud tertentu (Suryodiningrat dalam Rahmadina, 2017). Adapun tari yang menjadi jati diri atau identitas masyarakat tertentu, seperti tari Saman yang sangat kental dengan konten keindonesiaan dan budaya kenusantaraan (Alunaza, 2014). Selain itu, Siregar (2017) menyatakan bahwa tari Saman merupakan bentuk ungkapan kehendak atau keyakinan untuk tujuan-tujuan tertentu. Berbagai konsep matematika dapat digali melalui aktivitas masyarakat (Arisetyawan dkk, 2014; Abdullah, 2017; Maryati dan Prahmana, 2018), permainan tradisional (Risdiyanti dan Prahmana, 2018), kesenian (Putri, 2017; Sudirman, Rosyadi, dan Lestari, 2017), dan sebagainya. Lebih lanjut, Rosa dan Orey (2011) menyatakan bahwa masalah berbasis budaya yang berkaitan dengan kehidupan sehari-hari siswa perlu dijadikan sebagai bahan rujukan dalam mengembangkan pembelajaran matematika.

Oleh karena itu, penelitian ini mengambil peran untuk mengeksplorasi etnomatematika pada tarian tradisional yang ada dalam kebudayaan masyarakat Aceh serta nilai-nilai budaya yang terkandung di dalamnya. Harapannya hasil penelitian ini dapat digunakan sebagai konteks dalam pembuatan desain pembelajaran matematika, sehingga tercipta suatu desain pembelajaran matematika yang menyenangkan, dekat dengan kehidupan sehari-hari siswa, dan mengandung nilai budaya yang dapat membentuk karakter siswa ketika diterapkan didalam kelas.

\section{METODE PENELITIAN}

Penelitian ini menggunakan jenis penelitian kualitatif deskriptif sebagai jenis penelitian untuk mengungkap dan memperoleh informasi secara menyeluruh, 
meluas, dan mendalam (Prahmana, 2017).

Dalam prosesnya, penelitian ini menggunakan pendekatan etnografi, yaitu pendekatan empiris dan teoritis yang bertujuan untuk mendapatkan deskripsi dan analisis menyeluruh tentang budaya berdasarkan penelitian lapangan seperti yang telah dilakukan oleh Maryati (2018). Teknik pengumpulan data dalam penelitian ini terdiri atas dua bagian yaitu pengumpulan data pustaka diperoleh dari studi kepustakaan serta pengumpulan data lapangan yang terdiri dari tiga bagian observasi, dokumentasi serta wawancara. Hasil Observasi dan dokumentasi berupa catatan etnografi (catatan lapangan) yaitu tulisan yang dibuat selama kegiatan observasi dan dokumentasi. Instrumen dalam penelitian ini meliputi pedoman wawancara, pedoman (garis besar) observasi, dan dokumentasi.

Setelah data diperoleh, maka selanjutnya dianalisis berdasarkan Domain dan Taksonomi. Analisis domain dilakukan untuk memperoleh gambaran umum dan menyeluruh dari objek penelitian disertai penentuan kategori / domainnya dan pengelompokkan data sesuai kategori / domain. Pada penelitian ini data yang terkait dengan ide-ide matematika dikelompokkan sesuai lima kategori / domain yaitu domain etnomatematika seperti aljabar, geometri, kalkulus dan lain sebagainya. Selanjutnya analisis taksonomi dilakukan dengan cara menjabarkan domain-domain yang dipilih menjadi lebih rinci berdasarkan konsepkonsep matematika yang terdapat pada tarian tradisional pada pembukaan Asian Games 2018 yang ditampilkan dalam bentuk deskripsi.

\section{HASIL DAN PEMBAHASAN}

Hasil penelitian menunjukkan bahwa Etnomatematika ditemukan dalam tarian tradisional pada pembukaan Asian Games 2018 yaitu tari Saman. Etnomatematika dalam tari Saman pada pembukaan Asian Games 2018 dapat dilihat dari gerakan, pakaian, dan formasi tariannya.

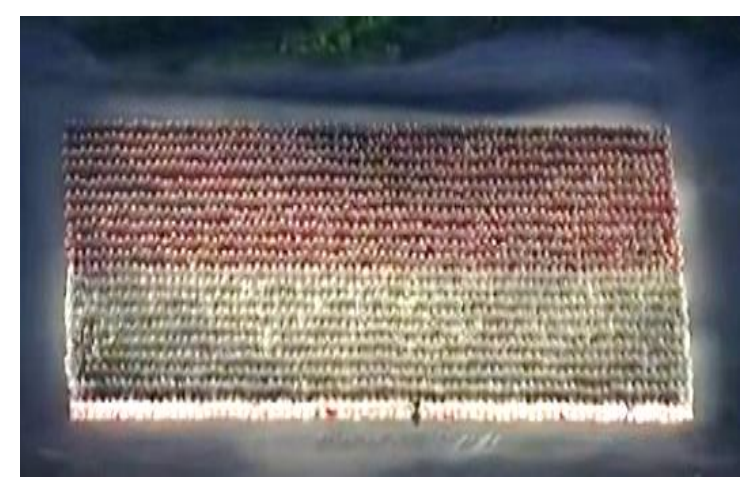

Gambar 1. Bentuk formasi Tari Saman yang menyerupai bentuk bangun datar persegi panjang

Pada Gambar 1, tampak suatu bentuk formasi penari Saman yang menyerupai persegi panjang. Tarian tersebut dilakukan oleh 1.600 penari. Jika diasumsikan bahwa jarak antara penari yang satu dengan yang lain adalah sama. Aspek matematis sekolah yang dapat dipelajari dari Gambar 1 adalah:

1) Sifat-sifat persegi panjang

Berdasarkan gambar tersebut dapat diamati bahwa:

a. banyaknya penari yang tampak dari depan dan yang tampak dari belakang sama yaitu 80 penari, sedangkan yang tampak dari samping kanan dan kiri juga sama yaitu 40 penari, hal ini menunjukkan bahwa sisi-sisi yang berhadapan sama panjang

b. formasi penari yang berada di 4 sisi pojok membentuk sudut $90^{\circ}$, hal ini menunjukkan bahwa keempat sisinya sama besar 
2) Luas persegi panjang

Konsep luas persegi panjang dapat ditemukan dengan menghitung jumlah penari seluruhnya yaitu 1.600. Untuk mendapatkan angka 1.600 dapat menggunakan cara mengalikan jumlah penari yang tampak dari depan dan jumlah baris ke belakang.

Diketahui bahwa jumlah penari yang tampak dari depan adalah 80 penari, kemudian jumlah baris ke belakang adalah 20 baris, berarti dapat dituliskan: $80 \times 20=1.600$

Jadi, dapat disimpulkan bahwa rumus menghitung luas persegi panjang adalah $L=p \times l$

3) Keliling persegi panjang

Konsep keliling persegi panjang dapat ditemukan dengan menjumlah banyaknya penari yang tampak dari depan, samping kanan, samping kiri, dan belakang.

Jumlah penari yang tampak dari depan adalah 80 penari, yang tampak dari samping kanan adalah 20 penari, yang tampak dari samping kiri adalah 20 penari, dan yang tampak dari belakang adalah 80 penari, berarti dapat dituliskan: $80+20+20+80=200$

Jadi, dapat disimpulkan bahwa rumus menghitung keliling persegi adalah $K=2 \times(p+l)$

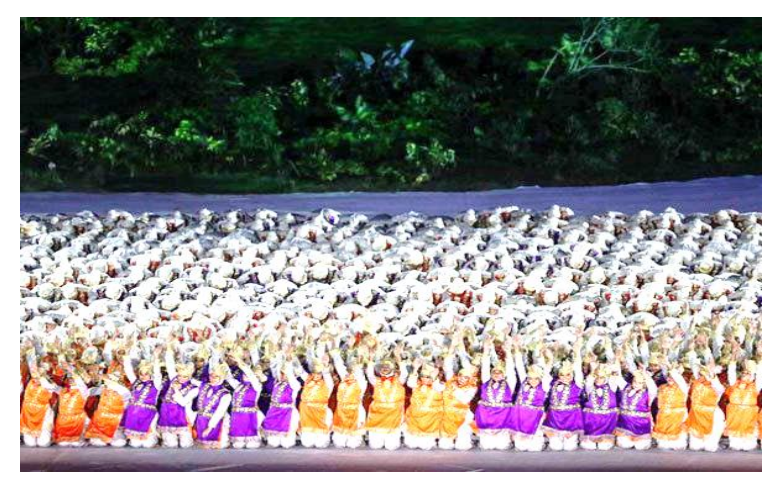

Gambar 2. Pertunjukan tari Saman pada acara pembukaan Asian Games 2018
Pada Gambar 2, tampak beberapa penari Saman pada acara pembukaan Asian Games 2018 yang mengenakan 2 kostum yang berbeda yaitu ungu dan oranye. Aspek matematis sekolah yang dapat dipelajari dari Gambar 2 adalah himpunan. Konsep himpunan yang dapat ditemukan pada Gambar 2 diantaranya:

(1) Himpunan semua penari Saman (himpunan semesta).

(2) Himpunan penari Saman yang mengenakan kostum berwarna ungu (himpunan bagian).

(3) Himpunan penari Saman yang mengenakan kostum berwarna oranye (himpunan bagian).

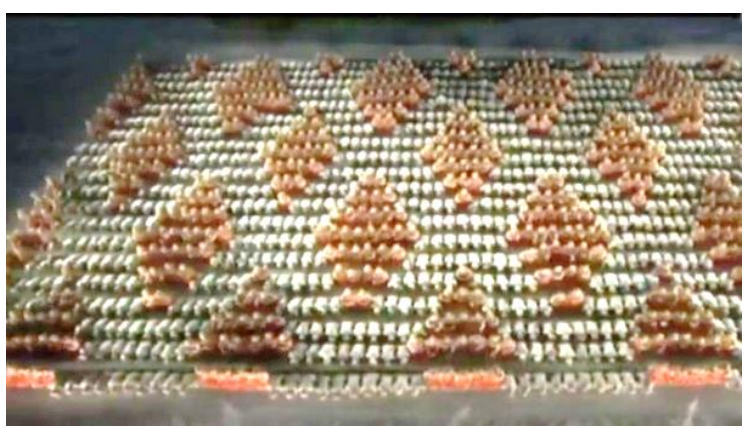

Gambar 3. Bentuk formasi Tari Saman yang menyerupai bentuk bangun datar belah ketupat

Pada Gambar 3, tampak suatu bentuk formasi penari Saman yang menyerupai belah ketupat. Penari yang membentuk formasi belah ketupat masing-masing terdiri dari 16 penari yang mengenakan kostum berbeda. Aspek matematis sekolah yang dapat dipelajari dari Gambar 3:

1) Sifat-sifat belah ketupat

Berdasarkan gambar tersebut dapat diamati bahwa:

a. belah ketupat mempunyai 4 sisi yang sama panjang

b. sudut-sudut yang berhadapan sama besar 
c. kedua diagonal saling berpotongan tegak lurus dan membagi dua sama panjang

2) Luas belah ketupat

Konsep luas belah ketupat dapat ditemukan dengan menghitung jumlah penari yang membentuk formasi belah ketupat yaitu 16. Untuk mendapatkan angka 16 dapat menggunakan cara mengalikan jumlah penari yang membentuk diagonal.

Diketahui bahwa diagonal pertama terbentuk dari 4 penari dan diagonal kedua terbentuk dari 4 penari juga. Maka dapat ditulis:

$4 \times 4=16$

Jadi, dapat disimpulkan bahwa rumus menghitung luas belah ketupat adalah $\mathrm{L}=\mathrm{d}_{1} \times \mathrm{d}_{2}$

3) Keliling belah ketupat

Konsep keliling belah ketupat dapat ditemukan dengan menjumlah banyaknya penari yang tampak dari depan, samping kanan, samping kiri, dan belakang.

Jumlah penari yang tampak dari depan adalah 4 penari, yang tampak dari samping kanan adalah 4 penari, yang tampak dari samping kiri adalah 4 penari, dan yang tampak dari belakang adalah 4 penari, berarti dapat dituliskan:

$4+4+4+4=16$

Jadi, dapat disimpulkan bahwa rumus menghitung keliling belah ketupat adalah $\mathrm{K}=4 \times \mathrm{s}$

\section{SIMPULAN}

Hasil penelitian ini menunjukkan bahwa tarian tradisional dalam kebudayaan masyarakat Aceh masih dilestarikan dan dijaga oleh masyarakat. Tari Saman mengajarkan nilai-nilai kekompakan. Konsep matematika yang ada dalam tari Saman pada acara pembukaan Asian Games 2018 tersebut berupa konsep bangun datar dan himpunan. Oleh karena itu, tarian tradisional ini dapat digunakan sebagai starting point atau konteks dalam pembuatan desain pembelajaran untuk anak sekolah dasar maupun sekolah menengah. Selain itu, dapat mengubah paradigma anak dan masyarakat bahwa matematika memiliki hubungan dengan aktivitas sehari-hari dan matematika memiliki hubungan dengan budaya serta dapat dipelajari dengan cara yang menyenangkan.

\section{DAFTAR PUSTAKA}

Abdullah, A. S. 2017. "Ethnomathematics in perspective of sundanese culture". Journal on Mathematics Education, Vol. 8 (1), pp: 1-16.

Alunaza SD, H. A. R. D. I. 2014. Analisa Diplomasi Budaya Indonesia Melalui Tari Saman Gayo dalam Mengukuhkan Identitas Nasional Bangsa (Doctoral dissertation, University of Muhammadiyah Malang).

Arisetyawan, A., Suryadi, D., Herman, T., Rahmat, C., dan No, J. D. S. 2014. "Study of Ethnomathematics: A lesson from the Baduy Culture". International Journal of Education and Research, Vol. 2 (10), pp: 681-688.

Dahlan, J. A., Permatasari, R. 2018. "Pengembangan Bahan Ajar Berbasis Etnomatematika dalam Pembelajaran Matematika Sekolah Menengah Pertama”. JNPM (Jurnal Nasional Pendidikan Matematika) Vol. 2 (1), pp: 133-150. 
Haryanto, et. all. 2017. "Ethnomathematics arfak (West Papua-Indonesia: Numeracy of Arfak". International Journal of Scientific \& Technology Research, Vol. 6 (9), pp: 325-327.

Kusuma, D. A., et al. 2016. "The role of ethnomathematics in West Java (A preliminary analysis of case study in Cipatujah)". Journal of Physics: Conf. Series 893.

Maryati \& Prahmana, R.C.I. 2018. "Ethnomathematics: Exploring the Activities of Designing Kebaya Kartini”. MaPan: Jurnal Matematika dan Pembelajaran, Vol. 6 (1), pp: 11-19.

Prahmana, R. C. I. 2017. Design research (Teori dan implementasinya: Suatu pengantar). Jakarta: Rajawali Pers.

Purnamasari, M., Isman, J., Damayanti, A., dan Ismah, I. 2017. “Upaya Meningkatkan Hasil Belajar Matematika terhadap Konsep Bangun Ruang Materi Luas dan Volume Balok dan Kubus Menggunakan Metode Drill Sekolah SMP Islam Al-Ghazali Kelas VIII". Fibonacci: Jurnal Pendidikan Matematika dan Matematika, Vol. 3 (1), pp: 45-52.

Putri, L. I. 2017. "Eksplorasi etnomatematika kesenian rebana sebagai sumber belajar matematika pada jenjang MI". Jurnal Pendas, Vol. 4(1).

Rahmadiana, N. S. 2017. Nilai Etika Dan Estetika Tari Ratoeh Jaroe pada Masyarakat Aceh di Kota Langsa (Doctoral dissertation, UNIMED).

Risdiyanti, I., dan Prahmana, R. C. I. 2018. "Etnomatematika: Eksplorasi dalam Permainan Tradisional Jawa". Journal of Medives: Journal of Mathematics Education IKIP Veteran Semarang, Vol. 2 (1), pp: 1-11.

Rohayati, S., Karno, K., dan Chomariyah, W. I. 2017. Identifikasi Etnomatematika pada Masjid Agung di Yogyakarta.

Rosa, M. dan Orey, D. C. 2011. "Ethnomathematics: the cultural aspects of mathematics". Revista Latinoamericana de Etnomatemática, Vol. 4 (2). pp: 32-54.

Sinambela, P. N. 2017. "Kurikulum 2013 dan Implementasinya dalam Pembelajaran". Generasi Kampus, Vol. 6(2).

Siregar, N. 2017. Relevansi Nilai-Nilai Tari Saman Terhadap Pendidikan Karakter dalam Pembelajaran IPS. Disertasi dan Tesis Program Pascasarjana UM.

Sudirman, S., Rosyadi, R., dan Lestari, W. D. 2017. "Penggunaan Etnomatematika pada Karya Seni Batik Indramayu dalam Pembelajaran Geometri Transformasi". Journal of Mathematics Education, Vol. 2 (1).

Vasquez, E. L. 2017. "Ethnomathematics as an Epistemological Booster for investigating Culture and Pedagogical Experience with the Young Offender or Prison School Communities". Journal of Education and Human Development, Vol. 6 (2), pp: 117-127. 